\title{
COMPUTERS IN WRITING INSTRUCTION
}

\section{HELEN J. SCHWARTZ*, THEA VAN DER GEEST $\dagger$ and MARLIES SMIT-KREUZEN}

\author{
*Indiana University of Indianapolis, Department of English, \\ 425 Agnes Street, Indianapolis, IN 46202, U.S.A. \\ †University of Twente, Department of Philosophy and Social Sciences, Post Box 217, \\ $7500 \mathrm{AE}$ Enschede, The Netherlands \\ $\ddagger$ St. Jorisstraat 48,5211 HB 's Hertogenbosch, The Netherlands
}

\begin{abstract}
For computers to be useful in writing instruction, innovations should be valuable for students and feasible for teachers to implement. Research findings yield contradictory results in measuring the effects of different uses of computers in writing, in part because of the methodological complexity of such measurements. Yet the computer seems to be a promising tool in several new, theoretically based approaches to writing instruction. Research of these kinds of computer applications should continue, paying attention to context variables that influence the implementation process importantly.
\end{abstract}

\section{Introduction}

Schools around the world are being asked to introduce students to computer use in the belief that computer literacy will be essential to personal, economic and national goals. For those who believe that computer use should be taught in connection with existing subject matter, it makes sense, for purely pragmatic reasons, to introduce students to computers through writing instruction - taught primarily either in their native languages or in the study of foreign language. Instruction in the mother tongue (sometimes called language arts) starts early in the curriculum and continues for a long time, with foreign language instruction being added as early as the seventh year of school. Therefore, all students, regardless of gender or curriculum specialization, would have some exposure to computers if used in language classes. And since software for language arts already exists in the form of computer-assisted instruction (CAI) as well as "tool" applications such as word processing, implementation seems feasible. However, unless there is educational gain for students and unless teachers can carry out their instructional goals without constant and continuing heroic effort, it is debatable whether goals for teaching computer literacy should or could be achieved in language classes.

Our questions, therefore, are: Is the use of computers valuable in writing instruction? 
And can potentially useful practices be implemented in the schools? In the following chapter we will discuss factors that may account for the mixed evaluation of computers in writing instruction to date. In the main sections we discuss the approaches to writing instruction in practice today, describe current and developing computer applications that support each of these approaches, and review research relevant to these computer applications. We end with a list of variables that should be considered in research if its effectiveness is to be tested. We present, therefore, not so much answers as a review of current evidence and guidelines for carrying out much needed research.

\section{Evaluation of Effectiveness}

Determining the value of computers for writing instruction cannot be seen apart from the way the computer is actually used. Yet, a definitive evaluation of such a developing phenomenon is clearly impossible. In this section we begin an assessment by noting overarching problems with the data and then sort evidence between hypothetical claims ("this theory plus this capability should produce this gain"), reports of experience ("my class did this and I noticed that"), and research (a systematic attempt to report perceptions whether through surveys or experiment, using qualitative or quantitative data).

\section{Problems with Data}

The first problem with the reported data is that the range of software being discussed is extremely diverse, ranging from highly structured computer-assisted instruction (CAI) with evaluative feedback and well-defined tasks (such as vocabulary and spelling drills) to software tools (such as an integratcd packagc with word proccssor, database and communications software). Improved hardware and newer kinds of software, such as planners and text checkers, have generally not yet been tested.

Second, the context variables for implementing use of the software are exceptionally complex. Different studies using the same tool - for example, a word processor may include differing amounts and content of instruction depending on many variables: the age of students, the length of training with word processors and duration of the study, the computer experience and training of the teachers, the type and number of assignments, the particular hardware and software. Many researchers don't even mention these variables in their reports, and often the research designs (especially in the earlier studies) are weak, not comparing groups systematically and working with a very limited number of subjects. Virtually no systematic longitudinal data are available. Even when the research design accounts for these variables, the results are hard to generalize.

Third, the computer tools themselves may be changing the research subject, the writing process. Some writers have trouble because they plan less (Grow, 1988; Haas, 1988) or miss surface errors because they comprehend text better in print than on the screen, except with high resolution screens such as on the Macintosh (Booth, 1984; Haas \& Hayes, 1986). 


\section{Claims and Reports about Computer Use in Writing Instruction}

The claims for using computers in writing instruction are diverse and impressive: that the computer affects the social, physical and cognitive processes of writing as well as the writing behavior, style and attitudes of students (Daiute, 1985; Schwartz, 1985; Van der Geest, 1986). Both students of lesser ability and higher ability seem to benefit as well as students of different ages (Becker, 1986). Computer use is hypothesized to improve both the quality and the quantity of written products (summarized in Hawisher, 1986).

In support of such claims, reports from teachers note significant changes in the classroom: children motivated to work longer on texts, understanding the process of writing better since they write with word processors, working in collaboration on pieces of texts that are revised on the basis of peer comments (Daiute, 1985). Although some research findings have been negative or have shown no effect of computcr use, if only part of the positive claims and reports are true for writing instruction and written products, the computer can be a very promising tool to improve the writing ability and motivation of generations of writers in the future.

\section{Research Results}

What do studies show about the overall effects of computer use in the writing classroom? Discussion of the results will be divided between uses of more structured programs and word processing, between effect on student work and on student attitudes. Use of structured CAI programs appears especially widespread at the lower grades, based on figures from over 2,100 computer-using schools in the United States in 1985 (Becker, 1986).

Collis (1988) carefully reviews research findings that show statistically significant results for such software. However, she raises important questions about the validity of these results. The greatest amount of software for language teaching (in mother tongue or foreign languages) involves CAI drill for discrete subskills, but an inventory of the skills included shows them concentrated on lower level skills (at the letter, word or sentence level) rather than covering the whole range of skills. Scorecard total: statistically significant gains for CAI but questions about the duration and impact of effects on the writing process

About the effects of word processing less is known, and results are more contradictory. In the Becker survey of American schools (1986), English teachers reported their perception that the use of computers improved writing: $21 \%$ of tcachers in grades $6-8 ; 69 \%$ of high school teachers. Yet use of word processing is not as widespread as use of CAI, in part because of difficulties in scheduling significant amounts of computer access. In research, Hawisher (1986) and Barker (1987) provide fine summaries that do more to show the complexity of measurement than to inspire confidence in the highly mixed results.

Most researchers agree in reporting improved attitudes toward writing and their own work, whether testing 9-12 year olds or professional writers, even with user-unfriendly mainframe computers (Hawisher, 1986; Barker, 1987). Especially with poor writers (Baer, 1986), students like writing better when using word processing. In Canada, 
Woodruff, Bereiter, and Scardamalia report that 12 sixth-graders found their writing easier, more enjoyable and better (although qualitative improvement was not confirmed by independent judging) (1981-82).

\section{Rationale for Further Study}

Why should governments and schools, researchers and teachers, continue their efforts to use computers in writing instruction in the absence of clear indications of value for effort and expense? We give two kinds of answers: a brazen appeal to experience and a hypothesis-oriented appeal to faith. When faced with the philosopher Berkeley's question "How do I know this stone exists?" the writer Samuel Johnson is reported to have kicked a stone in his path and claimed that as his answer. In a similar manner, when asked why it is worthwhile to study the effect of computers on writing and writing instruction, one can point out that few people who have used word processing with reasonable access have later rejected the new medium. Even people who suspect it may have some harmful effects on their writing do not want to give it up (Case, 1985). As word processing becomes the dominant technology for writing in the Information Age, the question is no longer whether people will use computers in writing instruction, but what the results will be if schools and instructors teach writing without reference to the dominant technology (Halpern \& Liggett, 1984).

A second, more interesting, answer appeals to faith, the often unacknowledged muse of research. A look at the dominant strategies in writing instruction shows that computers, especially with tools and with software currently under development, would seem to support these strategies and recommended practices much more effectively than traditional means. Yet most research findings are based on older word-processing programs and CAI, largely modelled on older, largely discredited pedagogical procedures emphasizing drill on discrete skills. The new, tool-based procedures are the hardest to implement because they require significant teacher training and support in addition to requiring significant amounts of time per student at the computer to be effective. That is, conditions for testing the effectiveness of the dominant strategies do not currently exist in most schools. If we hypothesize the value of butterflies, then it will not do to study only caterpillars.

\section{Strategies for Writing Instruction, Computer Applications and Research Results}

What butterflies do we expect to see? Current and developing computer software would seem to provide support for four strategies in writing instruction based on empirical and theoretical grounds: the "product" or subskills approach, a cognitive process view of writing, a social-process model and an integrated language approach (combining reading and writing, speaking, and listening). For each strategy, we will provide an explanation of the approach, computer applications and any research findings about the effectiveness of computers implementing this approach. 


\section{Writing as Subskills}

First, the traditional view sees writing as a collection of subskills to produce a product. If writing is seen as taking notes, writing an outline, choosing the correct words, checking for proper grammar and spelling the words correctly, then it makes sense to drill students in each of these skills. In this approach, activities need not be connected in a meaningful way; transference of skills is assumed. Much of existing practice in elementary schools and early language instruction still follows this model. However, a meta-analysis of writing research suggests that transference does not generally take place, and Hillocks (1986) cites studies that suggest that the subskill approach may even reduce the quality of written assignments.

Most of the existing software makes sense only in terms of this approach, with the large majority of commercial software designed for drill on specific aspects of punctuation, grammar, spelling and vocabulary building (Rubin, 1983; Collis \& Green, 1984). The advantages (research cited above) may be based on availability and ease of integration into the classroom rather than on quality and teacher enthusiasm.

Nevertheless, drill on subskills may be useful in some contexts. For example, entrance to college in the People's Republic of China requires high achievement on a standardized English exam (TOEFL), emphasizing grammar and sometimes arcane vocabulary. Therefore, drill for such performance (rather than for understanding in context) may prove meaningful in passing this threshhold requirement.

\section{The Cognitive Process Model}

Observation of writers suggests that writing is not the employment of subskills, but rather goal-driven behavior that calls for an orchestration of skills: setting goals for the task and audience, generating ideas from long-term memory, organizing, translating plans into text, revising in terms of goals and for correctness, with a monitor orchestrating which process comes to the fore at a particular point in the process. A model of writing as a cognitive process (in Fig. 3.1) shows that these parts are not separate skills, but are developed with reference to each other (Hayes \& Flower, 1980; Flower \& Hayes, 1981).

Someone can be a good speller and still make spelling mistakes when the monitor in translating is concentrating more on meeting goals than on correct spelling. Students with poor writing strategies do not know how to monitor their work effectively (Perl, 1979; Bereiter \& Scardamalia, 1987).

Computers would seem to be aids to using the process approach to teaching writing. As long as output can be saved and reloaded in compatible programs, teachers should be able to help students orchestrate different skills (see especially Rodrigues \& Rodrigues, 1986). The trend in software development seems to be away from single-skill CAI to tool applications that combine special functions in one program (Van der Geest, 1987). Software now on the market includes word processors with prewriting or planning modules, outliners, note-taking facilities (with search and copy functions that allow transfer to a word processing text), on-line handbooks, commenting windows (with text attached to specific points in the text), footnoting facilities (formatted according 


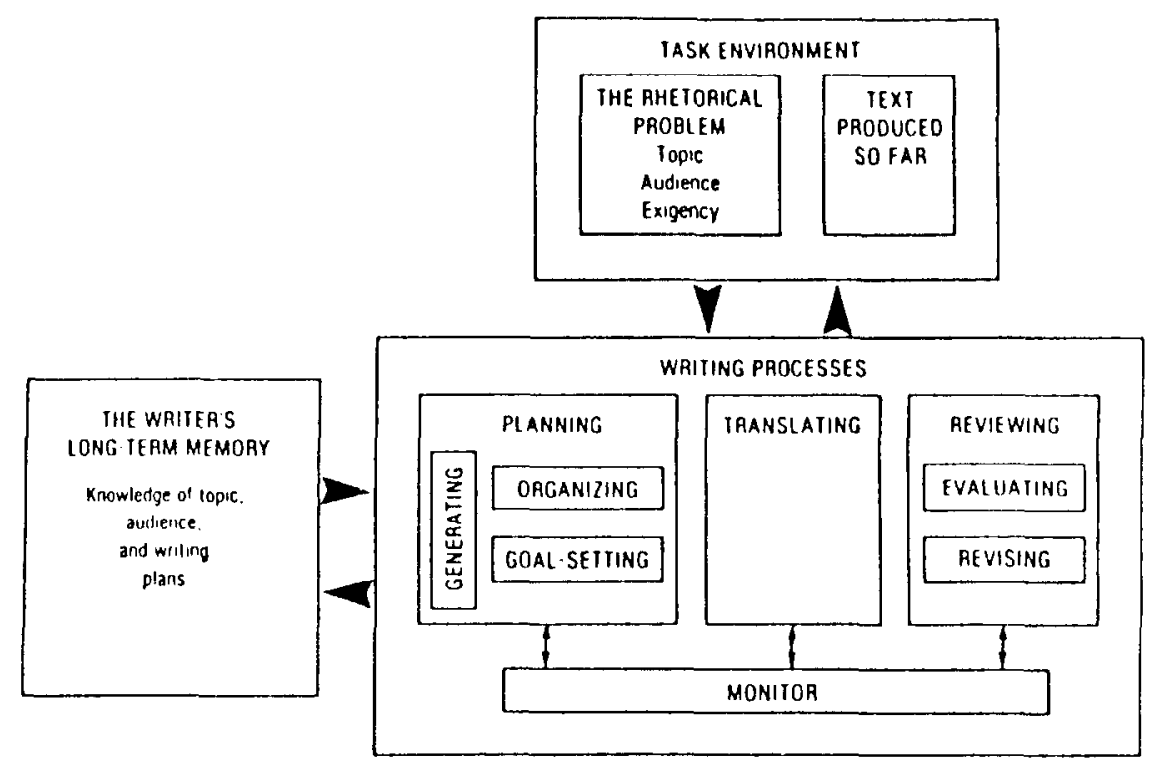

Figure 3.1. A model of cognitive processes in writing. From A Cognitive Process Theory of Writing by L. S. Flower and J. R. Hayes, College Composition and Communication, December 1981, 35, 365-387. Copyright 1981 by National Council of Teachers of English. Reprinted by permission.

to different styles of documentation), access to spreadsheets and self-created databases, graphics programs and communication software. Although no one program currently contains all these features, several programs that accept data from each other can combine a number of these functions.

Invention programs have often used "heuristics" as prewriting strategies (see Young, 1976) - to increase the quality and quantity of ideas that writers can use in their essays. Research has focused on the number of ideas produced (Burns \& Culp, 1980), structured heuristics compared to unstructured freewriting (Strickland, 1987), and the effects of peer comment on prewriting ideas (Schwartz, 1984; Gillis, 1987), but the studies are too diverse to generalize.

Word processing would seem theoretically to support a process approach to writing instruction since new ideas can be inserted, text can be moved or deleted easily. The possibility to save and reload texts would seem to support "orchestration" of efforts. Studies of parts of the writing process may help show computer effects more than those tabulating overall effects (Haas, 1988, 1989; Daiute, 1986; Haas \& Hayes, 1986; Hawisher, 1985 on revising). Although it is clear that computer use may affect composing processes, it is unclear what the nature of the impact is. Furthermore, new planning aids (such as outliners, notetaking databases and thesauruses) are largely untested, although McNealy's (1988) study of an on-line handbook suggests improved detection of error and transfer to revision of paper texts.

Word processing would seem to help students in revising because text is easily changed, but research on the revising process concludes that meaningful revision requires the writer to detect a problem, diagnose it and plan how to improve it (Flower, Hayes, 
Carey, Schriver, \& Stratman, 1986). Yet even if students detect a problem and diagnose it (or have a teacher's comments to help), they may not be able to revise, choosing to rewrite instead. It is no wonder then that studies of revision with computers show mixed results - with some students revising more, some the same and some mixed-especially when some studies specifically excluded instruction in writing (Hawisher, 1986). In his review of revision studies, Barker concludes that these studies show a problem with the understanding of "the nature of revision itself and how hard it is to pin down the effect of word processing on it" (1987).

In conclusion, we feel this approach is more valuable than the subskills approach. Although it is more difficult to research effectively, it seems more promising in the long run. We note, further, that the remaining approaches will often be seen to be compatible with the process model.

\section{Social and Cultural Dimensions of Writing}

A third approach emphasizes the social and cultural dimension of writing, as opposed to the cognitive approach of the process model. Although this approach has had different application in foreign and native language instruction, the theoretical basis is the same. Writing draws on socially developed skills of conversation as the child learns that her knowledge is not necessarily the same as her audience's. Just as the young child learns that she must give background or context to a story she speaks, she must later learn to anticipate the needs of an audience that is not there when she writes (Vygotsky, 1986). Students understand the use of writing for thinking and communication when they see composition as part of an ongoing conversation of humankind (Bruffee, 1984)-for example, when they write for an audience to deal with a real problem instead of doing a sterile exercise as an occasion for red ink. A meta-analysis of writing research shows that instruction tends to be more effective when it involves collaboration or a workshop approach than in the traditional teacher-centered classroom in which students get feedback only from the teacher and see only their own work against published models or samples provided by the teacher (Hillocks, 1986).

Computers appear to support collaborative approaches to writing. Computers provide a technology that facilitates collaborative work, through local-area networks (LAN) within a class or through disks mailed to students in other countries (Riel, 1984)-activities that can allow real exchange of information with other students. Within a computer lab, a number of computer-using teachers have commented on the creation of a collaborative attitude among students and faculty in computer labs, although this has been mainly noted in college settings with whole labs available on a drop-in basis for writing assigned in various classes. And the most promising results with invention programs (Gillis and Schwartz, cited above) involve feedback and comparison among students.

In both mother tongue and foreign language learning the recognition that language should be taught as it is actually used in various communicative situations has been reflected for years in the notional/functional (or communicative) approach (e.g., Leidse Werkgroep Moedertaaldidactiek, 1980). Although this approach in foreign language instruction is often equated with a greater emphasis on students' oral competence, its 
contribution to reading and writing skills should not be underestimated. The range of writing that students do is expanded. Different discourse goals (persuasion, explanation, expression, reflection, and inquiry) call for different forms of writing. Having a model of real-life conventions of communication is especially helpful for students who must use language functionally-for example using textbooks in foreign languages or studying abroad.

Computer applications include planning programs or planning text files or templates (created on the word processor) as a way of providing models for writing in different forms, a repeatable model that may help students internalize conventions or schematafor example, for writing a letter of complaint or a newspaper article. Research suggests that such structuring may be especially useful for slower learners (Kozma, 1987), although the question remains open whether this kind of modelling can be overly restrictive, leading to an overreliance on artificial structures.

\section{Integrated Language Study}

A fourth strategy, especially important in foreign language instruction, integrates the various aspects of language, arguing that writing cannot be separated from reading, listening and speaking. In language arts, researchers are increasingly studying the relationship of reading to writing (Shanahan \& Lomax, 1986; Marshall, 1987), seeing the distinction between the reception and production of text as artificial. "The best computer language arts activities will involve reading and writing and speaking and listening, ... [dealing] with communication that is meaningful and functional" for the student (Clements, 1985, p. 191). Practitioners have come up with methods that use word processing or CAI to integrate reading and writing. Students can use the same methods (for example, a planning file or topic sentence analysis) to analyze professionally written texts, those of other students or their own work.

Artificial intelligence is being used to create drill based on the student's real language use, with individual diagnosis of problems (Hull, Gall, Fox, Levin, \& McCutchen, 1987; Pijls, Daetamans, \& Kempen, 1987).

The development of hypertext media looks especially interesting in combining reading and writing, as well as listening and speaking in foreign language instruction. Hypertext allows easy access to information ancillary to the main text or activity. Normally with a book, there are several aids (that is, hypertexts) in addition to the main text, e.g., footnotes, a table of contents, information about the author, references and an index. However, computer hypertexts are now being designed that allow students to call up aids for machine-readable text. For example, a student might have on-line access to a dictionary, an atlas, or a music database.

Programs for foreign language instruction use interactive video disks to allow students to use their cultural and social knowledge of language to supplement learning. Such hypermedia "texts" can make available authentic incidents of language use--native speakers in their natural settings (for example, from television news clips or specially taped interviews). The segment can be replayed or rewound or the screen stopped. The student (or teacher presenting the lesson with the program) can cause the written text of the interview to be shown simultaneously, with the option of calling up a dictionary or a complete translation (Schoenmaker, Walner, \& Van Daalen, 1987). 
Little research on this approach is available, partly because measurement of the word-processing applications depends on accepted practices and materials, and these are only now being published. In addition, the hypermedia applications are also very new or still under development.

\section{Implementation Variables}

Research into classroom practice must show whether these applications are useful and feasible. However, a recent Wall Street Journal article (Bulkeley, 1988) notes a lack of teacher training, suitable software, and a shortage of machines in American schools. A 1985 survey (Becker, 1986) shows that the average American high school student used the computer for less than 20 minutes per week for language arts. Yet studies of classroom practice are needed to guide purchase of hardware and software and successful use of the computer in the language curriculum.

In assessing the value of implementation, the results depend on context variables that can be divided into those related to learning materials (hardware and software), teachers, students and administrative support.

\section{Variables Related to Materials}

(1) Access to computers (the number of computers and time available) Although reasonable amounts of interaction will vary with writing tasks, consistent and regular computer use over an extended period of time should be expected for measurable results.

(2) Location of the computers

A computer laboratory requires different planning than computers situated in a classroom, permanently or by scheduling. Have teachers had to adopt new strategies of instruction? by instigation from others?

(3) Quality of software and ease of use

Checking software with established rating organizations such as EPIE (Educational Products Information Exchange) in the USA or SCEN (Soft- and Courseware Evaluation Center) in the Netherlands can establish whether software is userfriendly and teacher-adaptable. Studies should also establish what supporting materials are available: do they match objectives, classroom use? Do they provide example material and lesson plans, especially with word processing?

(4) Technical support available

Are teachers required to look after the hardware and software themselves? Is technical help available in case of mishaps, for preparation and copying of disks? for printing of files? Do teachers have to supervise the laboratory when students are working there?

\section{Teacher-Related Variables}

(5) Familiarity with hardware and software 
Is the teacher comfortable with the software? aware of its potential in meeting classroom objectives? How effective is the teacher, and to what extent is teaching skill (as opposed to software excellence) responsible for educational outcomes?

(6) The teacher's perspective on instruction and teaching style Is the software consistent with the teacher's approach? If not, can it be adaptcd? What is the teacher's plan and teaching style? No two teachers will use the same material identically.

(7) The teacher's objectives

The objectives of instruction may vary widely from country to country (especially in foreign language instruction), or according to the ability level of the students. Objectives should influence software selection, and effects can only be considered in light of these original objectives.

(8) Teacher's time

Will teachers have to teach necessary computer skills to students during class time? Do teachers have to do preparatory work themselves? Are there shared files and colleagiality within a school or among a number of schools?

\section{Student-Dependent Variables}

(9) Students' familiarity with the software

(10) Age and level (grade/ability) of the students and learning styles

Are students mixed by ability level or by educational track (gymnasium vs. vocational school)? Are assignments individualized to take students' different learning styles into account?

(11) Attitude and access

What are the differences in access by ability level, gender or ownership of home computers?

\section{Administrative Variables}

(12) Rewards for teachers and stresses on them

What is the atmosphere in the school? the attitude of the principal and other administrators? Has release-line or reinbursement been given for training time and costs? Is there contact with other computer-using teachers? Does computer training increase job status or security?

(13) Support beyond the school level-within the district, at state/province/national levels

What policies or facilities help classroom teachers? Have changes been made in required syllabuses to include computer use?

(14) Budgeting

Priorities within an educational system are shown by allocations of money and changes brought about by computer use. Nevertheless, the economic level within a country/state/province will be an important factor in determining the amount of money available for computers, teacher training and student use. 
Most of these variables are influenced by the way teachers are trained-whether as part of their initial training or in-service. There is a clear trend away from introductory courses oriented toward hardware and computer literacy and toward curriculum-based applications and subject-specific training (Smit-Kreuzen, 1987), but no consensus has emerged for teacher training resulting in consistent and regular use of computers within a subject. The amount of time, the intensity, and the theoretical background of training will be dependent on the teaching objectives within various countries.

Research should examine models currently in use, taking into account the specific situations of operation. Two main models seem predominant at this time: the so-called "cascade" model in which one teacher is extensively trained and is then supposed to pass on that experience to colleagues; and the "support teacher" model in which a teacher is assigned to a school for a period of some months to help teachers across the curriculum with the introduction of computers within their subjects.

Clearly, it is going to be extremely difficult for a teacher to decide at which point and under which conditions the computer may be fruitfully used in writing classes. It is also going to be extremely difficult to measure the effect of the use of computers on students' written work in real classroom situations. Fortunately a comparative study of computer-using and non-using schools in over 20 nations is currently underway to study computer literacy in schools (Pelgrum \& Plomp, 1988), and this should provide a baseline of data as well as models for testing outcomes at the national, local, and student level of instruction. In addition, a report on computer use in Ontario may provide a model of how to study an emerging phenomenon, with the authors reporting on a wide range of applications with a large installed base of computers, but also with far-reaching study and plans at all levels-provincial, district, school, and classroom-with the goal of providing excellent software and sufficient computers for schools by 1995 (Fullan, Miles, \& Anderson, 1988).

\section{Conclusion}

In this chapter we have tried to set out the issues and the importance of finding answers when studying the value and feasibility of using computers in writing instruction. The innovation is an expensive endeavor. As with all important innovations, decisions about practice and funding must be made partly on faith or hunches before a fair summative evaluation can be made. Different answers to the variance of results in research to date have been presented. We feel that a fair, summative test of an important innovation cannot be made until reasonable formative cycles of review and developing practice have produced a mature phenomenon for study: in a test of butterflies, the data cannot focus exclusively on caterpillars.

Paradoxically, educational innovation is unlikely to be successful in the absence of tested and accepted quality in that innovation (Fullan, 1985), yet complex innovations require time and development to attain achieved (rather than hypothetical) value.

Without validation of practice, why should more money and effort be expended? Without an implementation that provides value in an implementable form, does it make sense to do a summative evaluation? Research (both formative and summative) needs 
to go on, even as the innovation is implemented, even as the instruments and procedures being tested are refined. Researchers and practitioners must work together to give the innovation a chance to fulfill its promise.

\section{References}

Baer, V. E. H. (1986). The Washington County, Maryland, IBM test project: Children, computers, and word processing. Paper presented at the Computers and Writing Conference, Pittsburgh PA.

Barker, T. (1987). Studies in word processing and writing. Computers in the Schools, 4 (1), 78-87.

Becker, H. J. (1986). Instructional uses of school computers, reports from the 1985 national survey. Baltimore: Johns Hopkins University, issue no. 1,2, 3.

Bereiter, C., \& Scardamalia, M. (1987). The psychology of written composition. Hillsdale NJ: Lawrence Erlbaum Associates.

Booth, W. C. (1984). Catching the overflow. College English, 46 (Feb.), 140-142.

Bruffee, K. A. (1984). Collaborative learning and the "Conversation of mankind". College English, 46, $635-652$.

Bulkeley, W. B. (1988). Computers failing as teaching aids. The Wall Street Joumal, June Gth.

Burns, H., \& Culp, G. (1980). Stimulating invention in English composition through computer-assisted instruction. Educational Technology, 28 (8), 5-10.

Case, D. (1985). Processing professional words: Personal computers and the writing habits of university professors. College Composition and Communication, 36 (3), 317-322.

Clements, D. H. (1985). Computers in early and primary education. Englewood Cliffs, NJ: Prentice-Hall.

Collis, B. (1988). Computers, curriculum and whole-class instruction. Issues and Ideas. Belmont, CA: Wadsworth Publishing Company.

Collis, B. A., \& Green, V. (1984). Language arts microcomputer software for the primary grades: What's available and what's it like? Prime Areas: Journal of the British Columbia Primary Teachers Association, 27 (1), 21-24.

Daiute, C. (1985). Writing \& computers. Reading MA: Addison Wesley.

Daiute, C. (1986). Physical and cognitive factors in revising: Insights from studies with computers. Research in the Teaching of English, 20, 141-159.

Flower, L. S., \& Hayes, J. R. (1981). A cognitive process model of writing. College Composition and Communication, 32, 365-387.

Flower, L., Hayes, J. R., Carey, L., Schriver, K., \& Stratman, J. (1986). Detection, diagnosis and the strategies of revision. College Composition and Communication, 37, 16-55.

Fullan, M. (1985). Curriculum implementation. In R. Husen \& N. Postlethwaite (Eds.), The international encyclopedia of education (pp. 1208-1215). Oxford: Pergamon Press.

Fullan, M. G., Miles, M. B.. \& Anderson, S. A. (1988). A conceptual plan for implementing the new information technology in Ontario schools. Ontario: Ministry of Education. (In press.)

Geest, Th. van der (1986). De computer in het schrijfonderwijs, perspectief voor een procesbenadering. (The computer in writing instruction, perspective for a process approach) Enschede: T.H. Twente, afd. Toegepaste Onderwijskunde. TO-reeks.

Geest, Th van der (1987). Teaching writing skills with computer-the development of a writing aid for secondary education. In J. Moonen \& Tj. Plomp (Eds.), EURIT 86: Developments in educational software and courseware. Oxford: Pergamon Press.

Gillis, P. D. (1987). Using computer technology to teach and evaluate prewriting. Computers and the Humanities, 21, 3-19.

Grow, G. (1988). Lessons from the computer writing problems of professionals. College Composition and Communication, 39, (2), 217-220.

Haas, C. (1988). How word processing affects planning in writing: The impact of technology. Paper presented at the annual meeting of the American Educational Research Association, New Orleans.

Haas, C. (1989). How the writing medium shapes the writing process: Effects of word processing on planning. Research in the Teaching of English. 23, (2), 181-202.

Haas, C., \& Hayes, J. R. (1986). What did I just say? Reading problems with the machine. Resenrch in the Teaching of English, 20, 22-37.

Halpern, J. W., \& Liggett, S. (1984). Computers \& composing. Studies in writing \& rhetoric. Carbondale, IL: Southern Illinois University Press.

Hawisher, $\mathrm{G}$. (1985). The effects of word processing on the revision strategies of college students. Doctoral dissertation, University of Illinois. 
Hawisher, G. E. (1986). Studies in word processing. Computers \& Composition, 4 (1), 6-31.

Hayes, J. R., \& Flower, L. S. (1980). Identifying the organization of writing processes. In L. W. Gregg \& E. R. Steinberg (Eds.), Cognitive processes in writing. Hillsdale.

Hillocks, G. (1986). Research in written composition. Urbana, IL: National Council of Teachers of English.

Hull, G., Ball, C., Fox, J. L., Levin, L., \& McCutchan, D. (1987). Computer detection of errors in natural language texts: Research on pattern-matching. Computers and the Humanities, 21, 103-118.

Kozma, R. B. (1987). Implication of research on composing for the design and use of computer-based writing tools. Paper presented at the Meadowbrook Conference on Computers in Writing Instruction, Rochester, MI.

Leidse Werkgroep Moedertaaldidactiek (1980). Moedertaaldidactiek. Muiderberg: Coutinho.

Marshall, J. D. (1987). The effects of writing on students' understanding of literary texts. Research in the Teaching of English, 21 (1), 30-63.

McNealy, M. S. (1988). Commenting on student writing: Some effects of computer assisted delivery. Doctoral dissertation. Pittsburgh, PA: Carnegie-Mellon University.

Pelgrum, W. J., \& Tj. Plomp (1988). The IEA study 'Computers in education': A multinational longitudinal assessment. Paper presented at ECCE' 88 , Lausanne.

Perl, S. (1979). The composing processes of unskilled college writers. Research in the Teaching of English, $13,317-336$.

Pijls, F., Daelemans, W., \& Kempen, G. (1987). Artificial intelligence tools for grammar and spelling instruction. Instructional Science, 319-336.

Riel, M. (1984). The Computer Chronicle Newswire: A functional learning environment for acquiring literacy skills. San Diego: University of California, Laboratory of Comparative Human Cognition.

Rodrigues, D., \& Rodrigues, R. J. (1986). Teaching writing with a word processor, Grades 7-13. Theory and Research into Practice pamphlet. Urbana, IL: ERIC Clearinghouse on Reading and Communication Skills and the National Council of Teachers of English.

Rubin, A. (1983). The computer confronts language arts: Cans and shoulds for education. In A. C. Wilkinson (Ed.), Classroom computers and cognitive science (pp. 201-208). New York: Acadenic Press.

Schoenmaker, J., Burghart, P., Walner, M., \& Van Daalen, K. A. T. (1987). An interactive graphic environment for learning foreign language. In J. Moonen \& $\mathrm{Tj}$. Plomp (Eds.), EURIT 86: Development in educational software and courseware (pp. 267-273). Oxford: Pergamon Press.

Schwartz, H. J. (1984). SEEN: A tutorial and user network for hypothesis testing. In W. Wresch (Ed.), The computer in compositional instruction, a writers' tool (pp. 47-62). Urbana, IL: National Council of Teachers of English.

Schwartz, H. J. (1985). Interactive writing, composing with a word processor. New York: Holt, Rinehart and Winston.

Shanahan, T., and Lomax, R. G. (1986). An analysis and comparison of theoretical models of the reading-writing relationship. Journal of Educational Psychology, 28, 116-123.

Smit-Kreuzen, M. L. (1987). The need for teacher training in the uses of the computer in (foreign) language teaching. Project report, University of Birmingham (UK), Dept. of English.

Strickland, J. (1987). Computers, invention and the power to change student writing. Computers \& Composition, 4 (2), 7-26.

Vygotsky, L. (1986). Thought and language. A. Kozulin (Ed.). Cambridge, MA: MIT Press.

Woodruff, E., Bereiter, C., \& Scardamalia, M. (1981-82). On the road to computer assisted compositions. Journal of Educational Technology Systems, 10 (2), 133-148.

Young, R. (1976). Invention: a topographical survey. In G. Tate (Ed.), Teaching composition: 10 bibliographical essays. Fort Worth: Texas Christian University Press.

\section{Biographies}

Helen Schwartz, Professor of English at Indiana University at Indianapolis, has consulted and published on computer use in writing since 1979. Her publications include Interactive Writing and the software SEEN and ORGANIZE. She chairs national committees to evaluate and implement computer use in college education.

Thea van der Geest, University of Twente (The Netherlands), is working on a research project in Computer Assisted Writing Instruction. She is developing SPIRIT, a writing instruction toolkit for secondary education, including a word processor and a planner. 
She is responsible for the national in-service Computers and Writing for teachers of mother tongue in Dutch secondary education.

Marlies Smit-Kreuzen studied English in The Netherlands and English Applied Linguistics in Great Britain. Working as a teacher and teacher trainer till 1987, she is currently living in Germany and involved in various teacher training programs and projects concerned with the introduction of the computer into the language curriculum. 